\title{
Método de avaliação da qualidade para ambientes e trabalho compartilhado
}

\author{
Renata Pizoni Mestranda em Engenharia de Produção, Universidade Federal de Santa Catarina (UFSC) - Brasil. \\ eng.renata.pizoni@gmail.com \\ Janaína Pereira Guimarães Mestranda em Engenharia de Produção, Universidade Federal de Santa Catarina (UFSC) - Brasil. \\ jana.cno2010@gmail.com \\ Edson Pacheco Paladini $\quad$ Doutor em Engenharia de Produção, Universidade Federal de Santa Catarina (UFSC) - Brasil. \\ repizoni@hotmail.com
}

\section{RESUMO}

O sistema de trabalho Coworking emerge a partir de ambientes de iniciativas colaborativas tendo como foco o compartilhamento espacial. É um formato no qual diversas empresas, coletivas ou profissionais liberais, dividem o mesmo espaço buscando, em especial, a partilha dos gastos. Esta pesquisa teve como objetivo geral desenvolver um modelo de gestão e avaliação da qualidade com base nos indicadores da qualidade online, inline e offline. Também pôde-se levantar um rol de melhoriaspara os problemas identificados. Em linhas gerais, o maior intuito deste trabalho foi desenvolver um modelo de avaliação da qualidade aplicável às demais empresas do ramo de coworking. A presente pesquisa é caracterizada como exploratória, de natureza aplicada e com método científico indutivo. 0 procedimento técnico utilizado para desenvolver a pesquisa foi um estudo de caso aplicado a duas empresas de Coworking situadas em Florianópolis/SC. Com base nos dados obtidos ao longo da pesquisa, pôde-se chegar a onze eficientes indicadores da qualidade e consequentemente, onze melhorias, todas congruentes aos itens e empresas estudados.

Palavras-chave: Economia compartilhada. Coworking. Gestão da qualidade. Indicadores da qualidade.

\section{Method of quality assessment for shared work environments}

\begin{abstract}
The Coworking system emerges from collaborative initiatives environments with a focus on space sharing. It is a format in which several collective companies or liberal professionals share the same space, in particular, seeking to share expenses. This research aimed to develop a quality management and evaluation model based on quality indicators online, in-line and off-line. A number of improvements could also be made to the problems identified. In general terms, the main purpose of this work was to develop a quality evaluation model applicable to other companies in the collaborative field. The present research is characterized as exploratory, of an applied nature and with an inductive scientific method. The technical procedure used to develop the research was a case study applied to two Coworking companies located in Florianópolis / SC. Based on the data obtained during the research, it was possible to reach eleven efficient indicators of quality and, consequently, eleven improvements, all congruent to the items and companies studied.
\end{abstract}

Keywords: Shared economy. Coworking. Quality management. Quality indicators. 


\section{INTRODUÇÃO}

No últimos tempos, a economia compartilhada vem criando base sólida nos mais diversos setores da economia mundial. Desde a música à hospedagem, este ramo vem ganhando cada vez mais participação em mercados antes controlados por poucas empresas. 0 efeito justifica-se não apenas pelos preços relativamente menores, mas principalmente, pela comodidade e praticidade dos serviços oferecidos que, além de utilizarem plataformas digitais seguras e interativas, trabalham com conceitos de redistribuição, realocando bens ociosos (MENDES; CEROY, 2015).

Conforme Martin (2016), o desejo de compartilhar informações, bens e serviços tende a derrubar as margens de lucro e inviabilizar monopólios e controle de preços pela elite financeira, sendo substituído por um modelo mais democrático e baseado no espírito colaborativo. Seguindo essa tendência de mercado, aparece uma nova forma de pensar o ambiente de trabalho, o Coworking.

Segundo o site Coworking Brasil (2017), no Coworking você encontra ambientes pensados para 0 trabalho autônomo, muito networking com pessoas de diferentes áreas e toda infraestrutura para receber clientes, além disso, menor custo se comparado ao aluguel de uma sala comercial convencional. A ideia do serviço é simples, visa profissionais independentes que procuram um espaço democrático em que possam desenvolver seus projetos sem o isolamento do home office ou as distrações de espaços públicos. Esses espaços buscam atender empreendedores e profissionais autônomos que geralmente estão iniciando suas empresas, sem muita previsão de quantas pessoas ou qual espaço precisarão nos primeiros meses ou anos (SOARES; SALTORATO, 2015).

O site Coworking Brasil surgiu em 2011 da iniciativa de diversos fundadores de espaços de coworking no Brasil. Dentro deste projeto, há o apoio à realização de censo há alguns anos. No censo de 2018, o Brasil aparece com 1.194 espaços ativos no país, dos quais 88 se encontram em Santa Catarina. Portanto, houve crescimento de $114 \%$ de 2016 para 2017 e mais $48 \%$ de 2017 para 2018. Considerando o Brasil, em média, cada espaço atende 21,2 coworkers e circulam 180 pessoas mensalmente. Cerca de $32 \%$ dos espaços que responderam ao questionário trabalham 24 horas por dia. Destes, $57 \%$ utilizam plano mensal, $22 \%$ fazem eventos mensais. Quanto a atuação dentro dos espaços, $75 \%$ se consideram multidisciplinares, $12 \%$ específicos para a indústria criativa, $5 \%$ para TI e tecnologia e $8 \%$ outras áreas. Quanto aos espaços, $36 \%$ estão em casas, $32 \%$ estão em conjuntos comerciais e $13 \%$ ocupam prédio completo, sendo $55 \%$ imóveis alugados e $45 \%$ imóveis próprios.

Tendo em vista a rápida expansão dos meios de negócios colaborativos e visando expandir conhecimento acerca desta nova temática, o presente artigo traz um modelo de gestão e avaliação da qualidade para Ambientes de Coworking. 0 trabalho se apresenta por meio de um estudo de caso aplicado em duas empresas de Coworking situadas em Florianópolis/SC. A avaliação da qualidade proposta na presente pesquisa tem por base os indicadores da qualidade para ambientes inline, offline e online. Estes indicadores evidenciam a relação da empresa com o mercado e seus consumidores. Também buscou-se apresentar melhorias aos processos estudados. 0 modelo de gestão e avaliação proposto também se apresenta apto para ser aplicado nas demais empresas do segmento.

\section{SUPORTE TEÓRICO}

Para dar embasamento à pesquisa, buscou-se para o suporte teórico estudos relevantes nas áres de Economia Compartilhada, Coworking, Gestão da Qualidade e Indicadores da Qualidade. 


\subsection{0 fenômeno Economia Compartilhada}

Diferentemente da tradicional economia capitalista, a Economia Compartilhada é baseada no compartilhamento de produtos ou serviços entre usuários dispostos a usufruir ou oferecer destes itens (FERREIRA et al., 2016).

Tanto recursos físicos quanto humanos fazem parte deste modelo de negócio colaborativo, tais como: veículos, alimentos, serviços, informações, moradias, tecnologias, entre outros. Pode-se citar como exemplo de empresas bem-sucedidas em processos de Economia Compartilhada: o Uber, o Cabify e o 99 no setor de transportes; a Airbnb e a Trivago no setor de aluguéis; e os aplicativos de delivery como o iFood e Pedidos Já (INVESTMENT STRATEGY \& RESEARCH, 2015).

A proposta de Economia Compartilhada não é nova, o escambo ou o compartilhamento de produtos ou serviços faz parte da história humana. Qualquer pessoa já compartilhou ou emprestou um livro, o carro, açúcar ao vizinho etc. No entanto, este comportamento nunca afetou a economia, não havia escala e as operações se restringiam geralmente às pessoas próximas (MENDES; CEROY, 2015).

Ainda há discussões na literatura sobre a origem do termo Economia Compartilhada. Para Shirky (2012), a Economia Compartilhada teve origem nos Estados Unidos na década de 1990, advinda dos grandes avanços tecnológicos, os quais geraram a redução de custos nas operações online peer-to-peer (peer-to-peer é um formato de rede de computadores para transmissão de arquivos e seu surgimento possibilitou o compartilhamento em massa de músicas e filmes). Já para Ferreira et al. (2016), o termo foi citado pela primeira vez em 2008 pelo professor de Harvard, Lawrence Lessig, o qual fez conexão entre a recessão econômica global e a redução do consumismo daquele momento.

Independentemente das datas de origem do termo, o fato é que esse mercado tem se popularizado cada vez mais e que estes acontecimentos acabaram atraindo clientes com novas exigências, incluindo a visão de sustentabilidade em suas necessidades (BOTSMAN; ROGERS, 2010). 0 desenvolvimento tecnológico foi fundamental para a fomentação do consumo conectado. Viabilizou a interação entre 0 vendedor e 0 comprador, entre a pessoa disposta a oferecer e quem está disposto a utilizar o serviço, gerando assim as transações com caráter de Economia Compartilhada (BRUNETE; BERTI, 2016).

Este modelo de consumo alternativo tem se disseminado cada vez mais e vem trazendo novas formas de consumo para produtos ou serviços que frequentemente ficavam ociosos ou eram subutilizados (MARTIN, 2016). O modelo também possibilitou um novo sistema de negócio entre pessoas desconhecidas, fundamentado pela troca e pelo compartilhamento de itens e não pela sua propriedade de fato (SCHOR, 2014).

Para Bostman e Rogers (2009), a Economia Compartilhada atende três tipos de sistemas:

Mercado de redistribuição - quando um produto sai de um ambiente onde não é mais necessário para outro onde o será, no preceito de "reduza, reuse, recicle, repare e redistribua";

Lifestylescolaborativos - fundamentado no compartilhamento de recursos como habilidade, tempo e dinheiro;

Sistemas de produtos e serviços - acontece quando o usuário paga pelo benefício do produto e não pelo produto em si, como por exemplo, pagar por um buraco na parede e não pela furadeira. Neste sentido, os ambientes de Coworking são caracterizados como ambientes colaborativos em sistemas de serviços, pois evidenciam a utilização do espaço em detrimento de tê-lo de fato.

Com relação ao crescimento dos modelos de negócios de Economia Compartilhada, Ferreira et al. (2016) afirmam que a previsão é que este mercado chegue a movimentar valores muito significativos nos próximos anos. Brunete e Berti (2016) corroboram com o citado por Ferreira et al. (2016). Os autores apresentam a estimativa de crescimento para a Economia Compartilhada nos próximos anos quando comparado à economia tradicional. Para esta estimativa foram citadas as cinco principais categorias da Economia Compartilhada, que são: compartilhamento de automóveis, empréstimo e crowdfunding (modalidade de investimento onde várias pessoas podem investir via internet pequenas quantias de dinheiro em um negócio, a fim de dar vida à ideia), hospedagens e acomodações, serviços autônomos on-line e distribuição de vídeo e música. 


\subsection{Ambientes de Coworking}

Segundo Moriset (2014), o sistema de trabalho denominado de Coworking emerge a partir de ambientes de iniciativas de colaboração voltado a profissionais de diferentes instituições, tendo como foco 0 compartilhamento espacial do trabalho. Trata-se de um formato no qual diversas empresas, coletivos ou profissionais liberais, dividem um mesmo espaço, buscando primordialmente a partilha dos gastos com o local de instalação. Visando a divisão de um espaço comum, o Coworking abre diversas possibilidades de proximidade entre os usuários, o que não ocorreria em um sistema de trabalho convencional.

Soares e Saltorato (2015) enfatizaram as principais características do estilo Coworking: abertura, sociedade, acessibilidade, sustentabilidade e colaboração. A partir deles é possível propor melhorias mais adaptáveis ao tipo de negócio em questão. Em contrapartida, Munhoz et al. (2013) afirmam que nem todos os coworkers dão abertura às colaborações, o que confirma o aspecto de heterogeneidade nos espaços de Coworking.

Portanto, o Coworking é vantajoso não somente para quem trabalha boa parte do tempo em casa. É uma solução com ótimo custo-benefício para empresas ou profissionais liberais que necessitem de espaço físico com agilidade, sem burocracia e nenhum investimento de preparação, como reformas ou aquisição de móveis e itens de decoração. Também libera o empresário de gerenciar a estrutura física, permitindo que ele se dedique totalmente ao seu negócio, aumentando a produtividade, reduzindo custos fixos e elevando a lucratividade. Desta forma, acaba sendo uma excelente opção para agilizar o processo de abertura de uma empresa e a rápida inserção no mercado, com espaço adequado disponível imediatamente para receber clientes e investidores (SOARES; SALTORATO, 2015).

\subsection{Gestão da qualidade}

Os conceitos da qualidade vêm mudando ao longo do tempo (PALADINI, 2009). Há alguns anos 0 conceito recaía somente sobre a durabilidade do produto, outrora sobre a marca. A marca denotava confiabilidade e confiança, o que ainda é aplicável. No entanto, o conceito de qualidade atualmente, tem recaído sobre aspectos um pouco mais subjetivos e às vezes difícil de mensurar, como 0 atendimento aos requisitos do cliente e do mercado. Pois acompanhar o mercado hoje é imprescindível para a gestão da qualidade.

Para Gurgel Júnior e Vieira (2002), na abordagem gerencial moderna a gestão estratégica da qualidade compreende o uso de técnicas comportamentais, o uso do conceito de clientes internos e externos, da qual a satisfação é o maior objetivo, a composição de equipes que pensam e executam os projetos, e o destaque aos processos e fluxos de trabalho, baseada em uma estruturação organizacional ad equada. Paladini (2011) corrobora ao afirmar que entender e apreciar as necessidades do cliente são fundamentais para uma empresa se desenvolver e se sustentar no atual mercado voraz. Por isso, as organizações buscam investir constantemente em conceitos modernos, atuais, inovadores, ou seja, diferenciados pela sua aderência ao momento presente ou por estarem à frente do seu tempo. Simultaneamente a isso, conceitos obsoletos vão sendo descartados.

A gestão da qualidade busca determinar quais características o mercado deseja e viabilizá-las. Dessa forma, a organização estaria tendo uma postura reativa, decorrente de uma informação previamente obtida. Segundo Paladini (2009), uma ação estratégica nessa situação seria como sair à frente e criar elementos que influenciam possíveis consumidores, ou seja, ao invés de descobrir necessidade, criá-las.

Os conceitos de multiplicidade e evolução mostram a constante preocupação da organização em atender os desejos do consumidor e, também, evidenciam que existem diversas formas de se alcançar isso (PALADINI, 2011). A multiplicidade busca direcionar toda a organização para 0 atendimento do consumidor, visando os múltiplos itens que ele considera relevante. Com o passar do tempo esses itens vão se alterando, por diversos fatores como opinião, postura, preferências, desejo etc. Surge a necessidade do monitoramento contínuo do comportamento de cada faixa de mercado atendida pela empresa. Dessa forma, configura-se o conceito de evolução, segundo o qual o consumidor se mantém fiel ao longo do tempo (futuro) se suas novas 
necessidades/expectativas forem sendo satisfeitas/superadas pelos produtos/serviços oferecidos (PALADINI, 2009).

A multiplicidade garante a fidelidade do consumidor hoje e é um diferencial estratégico face aos produtos que já estão no mercado. A evolução busca garantir a fidelidade do cliente no futuro, acompanhando a evolução do mercado ou estando à frente dele.

Enquanto que, para um produto, a qualidade reflete-se na sua conformidade com requisitos préestabelecidos que satisfaçam as expectativas dos clientes, a percepção de qualidade de um serviço é muito mais distinta e abrangente. A produção e consumo de um serviço ocorrem, geralmente, simultâneos. Além disso, outra particularidade dos serviços é a subjetividade na avaliação da qualidade, uma vez que o consumidor é parte integrante do processo produtivo (LOPES, 2014).

\subsection{Os indicadores como ferramenta de avaliação da qualidade}

A avaliação da qualidade apresenta papel significativo no gerenciamento das empresas e desenvolvêla pode significar o controle de inúmeras variáveis. Tão importante quanto produzir qualidade é avaliá-la. Através da avaliação da qualidade pode-se verificar, por exemplo, se a empresa está evoluindo ao longo do tempo, se os padrões pré-estabelecidos para a qualidade estão sendo atingidos, se os avanços tecnológicos empregados trouxeram os devidos benefícios, dentre outros aspectos (PALADINI, 2011).

Para desenvolver uma efetiva avaliação da qualidade, mecanismos com bases mensuráveis são imprescindíveis e os indicadores são componentes adequados para este fim. 0 objetivo é avaliar 0 avanço efetivo dos processos, aspecto fundamental no gerenciamento da qualidade. Conforme Paladini (2011), os indicadores da qualidade são essências para o processo de avaliação da qualidade. Ainda para o autor, os indicadores, além de mensuráveis, possuem como característica básica calcular o impacto da satisfação dos clientes e consumidores, para tanto, precisam ter aspectos como: objetividade, clareza, precisão, representatividade, viabilidade, visualização, ajuste, unidade, alcance e resultados. Ainda em conformidade com o autor, os indicadores estão associados a ambientes específicos de produção da qualidade, tais como:

Ambiente da qualidade inline: enfatiza o processo produtivo em si, possui como características fundamentais a ausência de defeitos, a capacidade de produção, as estratégias de operação, otimização dos processos, atendimento às especificações e a produtividade.

Ambiente da qualidade offline: destaca as atividades que dão suporte ao processo produtivo, como o PCP; suporte a produção no caso da manutenção por exemplo, projeto de marketing, setor relacionado a segurança do trabalho, recrutamento e qualificação do pessoal etc. Em suma, a qualidade offline está direcionada para a ação de pessoas e de setores que não atuam diretamente com o processo produtivo.

Ambiente da qualidade online: aponta as relações entre a empresa, e o mercado, investindo na eficácia da empresa e caracterizada pela percepção das necessidades de consumidores e clientes, além da imediata reação às mudanças.

Para a elaboração da avaliação, o indicador deve possuir relação com o ambiente de análise, sendo indispensável também, associá-lo a quatro informações básicas, que são:

Objetivo: fase inicial e fundamental de todo o processo de avaliação do indicador. 0 objetivo do indicador direciona a ação de avaliação da qualidade;

Justificativa: trata da determinação quanto à relevância de se prosseguir com tal avaliação, não há como desenvolver uma avaliação se não se conhece o motivo de fato;

Ambiente: os ambientes da qualidade já foram descritos acima, mas em resumo tratam-se de (1) ambiente inline para indicadores de desempenho; (2) ambiente offline para indicadores de suporte e (3) indicadores online para indicadores da qualidade de fato;

Padrão: já o padrão serve de referência para saber se houve evolução no processo avaliado ou não, possibilitando a comparação entre meta estabelecida e nível atingido. 


\section{PROCEDIMENTOS METODOLÓGICOS}

Estudos científicos configuram-se pelo uso de procedimentos metodológicos. Conforme Marconi e Lakatos (2010), o método é um composto de atividades que outorgam e fundamentam os objetivos do trabalho. Abaixo apresenta-se sucintamente o enquadramento da metodologia usada na execução do presente artigo:

Natureza: Aplicada;

Método Científico: Indutivo;

Abordagem: Qualitativa;

Objetivos: Exploratórios;

Procedimentos técnicos: estudo de caso.

0 trabalho é de natureza aplicada, porque tem o intuito de apurar o nível de qualidade de ambientes de trabalho compartilhados. No que tange ao método científico, a pesquisa é caracterizada como indutiva dado que tem por finalidade levar a conclusões, cujo o conteúdo é mais amplo do que das premissas que se baseou (MARCONI; LAKATOS, 2010).

A abordagem do estudo é considerada como um estudo de caso qualitativo posto que tem destaque na obtenção de informações sobre a percepção da qualidade de ambientes Coworking (MARCONI; LAKATOS, 2010). Já no que se refere aos objetivos, trata-se de um estudo exploratório, visto que os estudos exploratórios permitem ao pesquisador desenvolver sua experiência sobre um determinado problema (GIL, 2010). E, finalmente, no que corresponde aos procedimentos técnicos, o presente trabalho é um estudo de caso pois conforme Miguel (2011), o estudo de caso consiste na utilização de métodos para o recolhimento de informações, não seguindo uma linha rígida de investigação.

Quanto ao instrumento de coleta e análise dos dados, foi utilizado a aplicação de questionário aplicado aos coworkers, profissionais que fazem parte do ambiente de trabalho. 0 viés do questionário compreende questões a respeito do serviço prestado pela empresa e pelo atendimento no site. Desta forma, serão coletadas as informações necessárias para a definição de uma lista de indicadores de qualidade. Assim, conforme Paladini (2011), são os usuários (coworkers) que determinam o nível de qualidade do serviço utilizado.

No que tange ao questionário, foram estudados dois ambientes de coworking na cidade de Florianópolis/SC e o público-alvo entrevistado foram os usuários dos ambientes. Foram 17 entrevistados e o questionário contemplou perguntas a respeito do serviço prestado pela empresa de coworking, como espaço físico, satisfação com os serviços oferecidos, compreendimento das informações recebidas, vantagens e desvantagens observadas pelos usuários. Os indicadores da qualidade e as melhorias propostas foram gerados a partir dessas respostas.

Cabe salientar que os indicadores desenvolvidos estão associados aos ambientes específicos de produção da qualidade, como estratégias de operação e atendimento as especificações dos usuários (ambiente da qualidade inline), suporte aos processos como marketing e planejamento de novos pacotes de vendas (ambiente da qualidade offline) e, por fim, atividades específicas sobre a percepção da necessidades dos clientes (ambiente da qualidade online).

\section{ESTUDO DE CASO}

Este capítulo apresenta o estudo de caso.

\subsection{Caracterização da empresa}

Para o presente estudo de caso foram selecionadas duas empresas de Coworking localizadas em Florianópolis/SC. As empresas oportunizam um ambiente de desenvolvimento profissional, com intuito de quebrar barreiras físicas e os modelos de trabalho habituais. 
Imagem 1 - Ambientes de trabalho na empresa $X$

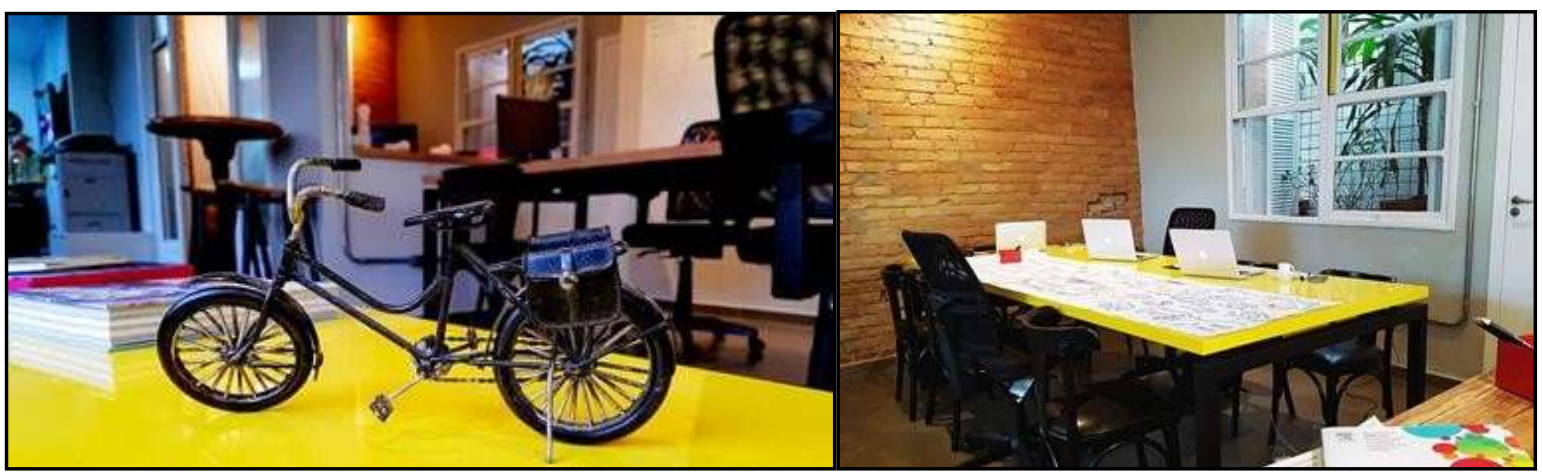

Fonte: Facebook da Empresa (2017).

A empresa $X$ disponibiliza toda a infraestrutura para o empreendedor desenvolver tranquilamente seu trabalho e seu negócio, além de oferecer ambientes próprios para realização de eventos como workshop, treinamentos ou cursos. Atualmente, a empresa apresenta os seguintes serviços que são divididos em cinco planos:

i.Virtual: esse plano inclui endereço comercial, serviço de impressão, sem plano de horas de utilização pelo valor de $\mathrm{R} \$ 95,00 /$ mês;

ii.Day Use' 0 valor é pago pelo dia em que usar. Por um período de até 5 horas é pago o valor de $R \$ 50,00$. Já por um período de até 11 horas o valor pago é de $R \$ 65,00$. No entanto, nesse plano não está incluso sala de reunião;

iii.Estação 1/2: este por sua vez oferece a estação de trabalho em mesa compartilhada, durante meio período (manhã ou tarde) pelo valor de R\$390,00 /mês;

iv.Estação Integral: o plano compreende a estação de trabalho em mesa compartilhada em turno integral pelo valor de $\mathrm{R} \$ 690,00$ /mês;

v.Estação Flex inclui a estação de trabalho em mesa compartilhada no turno integral, e com opção de utilização noturna das 18:00h às 23:00 h (valores sob consulta).

Imagem 2 - Ambientes de trabalho na empresa $Y$

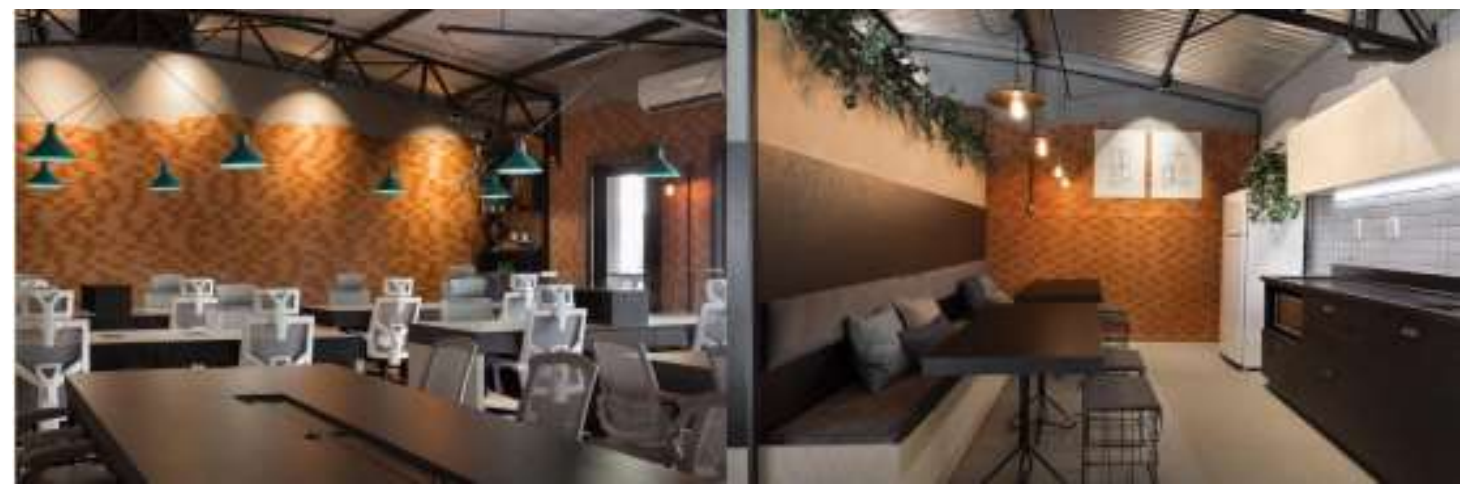

Fonte: Facebook da Empresa (2018).

A empresa $Y$ disponibiliza toda a infraestrutura para o empreendedor desenvolver tranquilamente seu trabalho e seu negócio, oferece também ambientes próprios para realização de eventos como workshop, treinamentos ou cursos e além disso, dispõe de um bar. Atualmente, a empresa apresenta os seguintes serviços que são divididos em cinco planos:

i. Spot rotativo: este plano inclui wi-fi, recepcionista, posição variável no salão, coffee break livre, endereço comercial, perfil no site da empresa, descontos em parcerias, sala de reunião (planos 80h, 120h e ilimitado)*. Para planos de 40 horas mensais, o valor varia de $R \$ 159,00$ por mês a $R \$ 129,00$ por mês em plano anual. Para planos de 80 horas mensais, o valor varia de $R \$ 319,00$ mensais a $R \$ 259,00$ por mês em plano anual. Para horas ilimitadas, o valor varia de $R \$ 599,00$ mensais a $R \$ 479,00$ por mês em plano anual. 
ii. Spot fixo: nesta opção está incluso a exclusividade de um spot fixo, wi-fi + cabo, período integral, recepcionista, posição fixa no salão, endereço comercial, endereço fiscal, descontos em parcerias, locker privativo, coffee break livre, perfil no site da empresa, gaveteiro, acesso ilimitado ( $8 \mathrm{~h}-20 \mathrm{~h}$ ), 4 horas de sala de reunião. Para este serviço, o plano mensal sai a $\mathrm{R} \$ 850,00$ mensais e $\mathrm{R} \$ 650,00$ por mês em plano anual.

iii. Day use Serviço por um dia ou algumas horas incluindo wi-fi, recepcionista, posição variável no salão, coffee break livre. Os valores variam de $R \$ 7,00$ por hora a $R \$ 40,00$ por 8 horas.

iv. Reuniões: a empresa possui 4 salas de reunião totalmente equipadas para 3, 5 e 9 pessoas, com wifi + cabo, áudio/vídeo, coffee break, TVs 4 K nas 2 salas maiores. Para a menor sala, os valores variam de $R \$ 40,00$ por hora a $\mathrm{R} \$ 270,00$ por 8 horas. Na sala média, os valores variam de $\mathrm{R} \$ 50,00$ por hora a $\mathrm{R} \$ 340,00$ por 8 horas. Na maior sala, os valores variam de $\mathrm{R} \$ 70,00$ por hora a $\mathrm{R} \$ 470,00$ por 8 horas.

v. Escritório Virtual: Serviço de endereço fiscal para abertura de empresa ou filial, recepção de clientes (8h às $20 \mathrm{~h}$ ) recebimento de correspondências e encomendas, uso do endereço comercial. Os valores variam de $R \$ 200,00$ mensais a $R \$ 160,00$ por mês em Plano Anual.

vi. Eventos: Aluguel do espaço para eventos com estrutura completa de auditório / sala de aula, projetor e telão, coffee break, ambiente climatizado. Os valores para dias de semana são sob consulta e disponibilidade, e nos fins de semana custam $\mathrm{R} \$ 150,00$ por hora.

\subsection{Avaliação da qualidade}

Os serviços prestados pelas empresas foram avaliad os à partir de perguntas direcionadas aos clientes. A seguir, apresentam-se as perguntas aplicadas no questionário.

\section{Do serviço prestado pela empresa - atendimento por meio do uso de seu site}

a) Como você ficou sabendo so bre esse ambiente de trabalho do Coworking?

b) Você teve acesso ao site da empresa?

c) Apresentou alguma dificuldade para acessá-lo?

d) O que você achou sobre sua página da empresa na internet, atendeu suas expectativas e sanou todas dúvidas sobre a empresa?

e) O que mudaria ou incluiria no site?

\section{Do serviço utilizado}

a) Antes de utilizar o espaço colaborativo, já conhecia o modelo de trabalho Coworking? Se sim, como tomou conhecimento desse tipo de serviço?

b) Quais serviços oferecidos você utiliza?

c) O que mais o motivou a vir para esse espaço de Coworking?

d) 0 ambiente compartilhado permite que você desempenhe suas tarefas conforme planejou? Por quê?

e) 0 custo $x$ benefício do Escritório Virtual compensa para você?

f) Para você qual o principal diferencial desse novo ambiente de trabalho?

g) Há alguma coisa que não lhe agrade nesse novo ambiente de trabalho?

h) A empresa correspondeu às suas expectativas?

i) Como você avalia a estrutura física do ambiente de Coworking da referida empresa?

j) Como você avalia 0 atendimento nesse ambiente?

k) Já utilizou outro espaço de Coworking antes? Se sim, por que deixou de utilizar?

\section{ANÁLISES E DISCUSSÕES}

Com o objetivo de atender aos múltiplos itens que os consumidores consideraram relevantes e para que o serviço atenda o preceito de adequação ao uso, foram propostas algumas melhorias nos serviços das empresas de Coworking estudadas. As melhorias tiveram como embasamento as respostas dos questionários.

As primeiras melhorias sugeridas são no processo de interação via site da empresa com seus usuários. 
Pensando em uma maior interatividade dos usuários com o espaço, visto ainda que o perfil dos usuários é "jovem empreendedor", o espaço da empresa X poderia ampliar seu atendimento pelo site ou um aplicativo próprio. A primeira melhoria a ser explanada seria a disponibilização de contratação de pacotes pelo próprio site ou aplicativo próprio, desafogando os serviços da recepcionista doespaço, assim como a empresa Y faz pelo site. Além da contratação pelo site da empresa Y, esta possui parceria com outra empresa que, através de site e aplicativo, vende planos de acesso a espaços de coworking em vários lugares do Brasil.

A empresa Y possui algumas funcionalidades no site para facilitar 0 acesso do usuário: consulta de disponibilidade de serviços, histórico de atendimentos/recados já recebidos, consulta ao histórico de compras, emissão de segunda via de boletos e notas fiscais, cadastro de pessoas para assinar ou receber encomendas. Tais funções foram elogiadas pelos entrevistados, fazendo uma ressalva para as cores do site. Portanto, tais funções são recomendadas à empresa X. Visando melhorias, recomenda-se outras funções como controle de impressora e impressões, acesso de equipes, dentre outras. Dessa forma o consumidor paga apenas uma vez por mês, englobando o valor do seus pacotes e adicionais, e os agendamentos são feitos todos online, sem necessidade de uma recepcionista para fazer essas tarefas.

Já com relação às melhorias no serviço, a primeira seria com relação ao estacionamento. Oferecer serviço de estacionamento para os clientes que visitam os empreendedores no Coworking se mostrou de extrema necessidade.

No que tange aos valores praticados, sugere-se à empresa $X$ lançar outras opções de pacotes, como plano anual e semestral, oportunizando preços mais acessíveis e buscando a fidelização do cliente, estratégia utilizada com sucesso pela empresa Y. A criação de um plano de pontuação aos usuários também pode ser uma boa estratégia comercial para ambas as empresas. 0 consumidor ganha pontuações de acordo com os gastos no espaço. Esses pontos podem ser trocados por serviços do espaço ou upgrades de plano, por exemplo. 0 que torna mais um artifício de fidelização de cliente.

Remetendo-se às necessidades dos consumidorese atentando-se ao conceito de multiplicidade, sugere-se que os espaços de Coworking possam oferecer parcerias com serviços de apoio estruturado aos usuários, como por exemplo serviços de contabilidade, comunicação, recursos humanos e tecnologia da informação, especializados em "micro empreendedores coworkers". Desta forma, os clientes do espaço já teriam toda assessoria básica necessária ao funcionamento de uma pequena empresa. As vagas para estes serviços poderiam ser preenchidas pelos próprios coworkers do espaço, fomentando assim o espírito de colaboração e alcançando a fidelização dos clientes.

E por final, outro benefício da melhoria sugerida é a oportunidade de criar e divulgar espaços para várias outras profissões que ainda não aderiram em massa ao espaço Coworking, como a Contabilidade e Recursos Humanos, por exemplo. Já que conforme Soares e Salterato (2015), as profissões mais encontradas nesses espaços são das áreas de informática, designer, comunicação, arquitetura e engenharia.

Um novo nicho a explorar são as futuras gerações, filhos dos coworkers. Para isso, uma possível melhoria seria disponibilizar um espaço no ambiente de coworking para os filhos pequenos de seus clientes. Um local onde poderão se desenvolver em segurança, acompanhadas por cuidadoras, realizando atividades de desenvolvimento motor, brincadeiras artísticas, vivências sensoriais e serão incentivadas a desenvolver a autonomia e a socializar com crianças de várias idades, tudo isso enquanto seus pais trabalham. Tal serviço pode estar incluso em um pacote específico de uso do escritório compartilhado, permitindo aos clientes dispor de um espaço de trabalho profissional e de cuidados especializados para as crianças por um preço compatível com o que gastariam em apenas um desses serviços, se contratados separadamente.

\section{RESULTADOS}

De acordo com Paladini (2011), a necessidade de desenvolver métodos de avaliação objetivos tem determinado o crescente interesse das organizações em investir em mecanismos quantitativos de fácil visibilidade. A partir desse pressu posto, foram desenvolvidos indicado res para as melhorias propostas no item 5. 
Os indicadores propostos para as melhorias no processo de interação da empresa estudada com seus usuários (site) são:

Quadro1 - Indicadores

\begin{tabular}{|c|c|c|c|}
\hline Indicador & Objetivo & Justificativa & Ambiente \\
\hline 1 & $\begin{array}{c}\text { Avaliar a aceitação da nova } \\
\text { forma de contratação do } \\
\text { serviço }\end{array}$ & $\begin{array}{c}\text { Determinar se haverá aumento } \\
\text { na contratação dos pacotes }\end{array}$ & Online \\
\hline 2 & $\begin{array}{c}\text { Avaliar a redução do tempo } \\
\text { investido em procedimentos } \\
\text { de agendamento de horários }\end{array}$ & Reduzir a burocracia interna do & Offline \\
\hline
\end{tabular}

Fonte: Elaborado pelos autores (2017).

Quadro2 - Relação do indicador com o ambiente de avaliação

\begin{tabular}{|c|c|c|c|c|}
\hline Indicador & Padrão & Elemento & Fator & Medida \\
\hline 1 & $20 \%$ no mínimo & Vendas & $\begin{array}{r}\text { Acréscimo na aquisição de } \\
\text { serviços após a liberação da } \\
\text { contratação pelo site/ app }\end{array}$ & Percentual/mês \\
\hline 2 & $40 \%$ no mínimo & $\begin{array}{c}\text { Tempo de } \\
\text { agendam } \\
\text { entos }\end{array}$ & $\begin{array}{c}\text { Redução do tempo gasto para } \\
\text { agendamentos pela } \\
\text { recepcionista por mês }\end{array}$ & Percentual/mês \\
\hline
\end{tabular}

Fonte: Elaborado pelos autores (2017). 
Quadro 3 - Relação do indicador com o ambiente de avaliação

Fonte: Elaborado pelos autores (2017)

\begin{tabular}{|c|c|c|c|}
\hline Indicador & Objetivo & J ustificativa & Ambiente \\
\hline 1 & $\begin{array}{l}\text { Avaliar a aceitação do } \\
\text { novo serviço }\end{array}$ & $\begin{array}{l}\text { Determinar se haverá aumentos nas visitas dos } \\
\text { consumidores dos coworkers }\end{array}$ & In line \\
\hline 2 & $\begin{array}{l}\text { Determinar níveis de } \\
\text { rotatividade dos } \\
\text { coworkers }\end{array}$ & $\begin{array}{l}\text { Determinar se haverá redução da } \\
\text { rotatividade dos coworkers apósa } \\
\text { implantação deestacionamento }\end{array}$ & Online \\
\hline 3 & $\begin{array}{l}\text { Determinar níveis de } \\
\text { rotatividade dos } \\
\text { coworkers }\end{array}$ & $\begin{array}{l}\text { Determinar se haverá redução da } \\
\text { rotatividade dos coworkers após implantação } \\
\text { de planos mais longos }\end{array}$ & Online \\
\hline 4 & $\begin{array}{c}\text { Avaliar a aceitação do } \\
\text { novo serviço }\end{array}$ & $\begin{array}{l}\text { Determinar se haverá troca de plano } \\
\text { dos consumidores }\end{array}$ & Online \\
\hline 5 & $\begin{array}{l}\text { Avaliar a aceitação do } \\
\text { novo serviço }\end{array}$ & $\begin{array}{l}\text { Determinar se haverá aumento na } \\
\text { contratação dos pacotes por novos clientes }\end{array}$ & Online \\
\hline 6 & $\begin{array}{l}\text { Determinar níveis de } \\
\text { rotatividade dos } \\
\text { coworkers }\end{array}$ & $\begin{array}{l}\text { Determinar se haverá redução da } \\
\text { rotatividade dos coworkers após implantação } \\
\text { de programa de pontuação }\end{array}$ & Online \\
\hline 7 & $\begin{array}{c}\text { Avaliar a aceitação do } \\
\text { novo serviço }\end{array}$ & $\begin{array}{c}\text { Determinar se haverá aumento na contratação } \\
\text { de pacotes por clientes dos coworkers }\end{array}$ & Online \\
\hline 8 & $\begin{array}{l}\text { Avaliar a aceitação do } \\
\text { novo serviço }\end{array}$ & $\begin{array}{c}\text { Determinar se haverá aumento na contratação } \\
\text { dos pacotes por novos } \\
\text { clientes }\end{array}$ & Online \\
\hline 9 & $\begin{array}{c}\text { Avaliar a aceitação do } \\
\text { novo serviço }\end{array}$ & $\begin{array}{c}\text { Determinar se haverá aumento na contratação } \\
\text { dos pacotes pornovos clientes de áreas novas } \\
\text { noescritório }\end{array}$ & Online \\
\hline
\end{tabular}


Quadro 4 - Estrutura dos indicadores

\begin{tabular}{|c|c|c|c|c|}
\hline Indicador & Padrão & Elemento & Fator & Medida \\
\hline 1 & $\begin{array}{l}15 \% \text { no } \\
\text { mínimo }\end{array}$ & $\begin{array}{c}\text { Aumento nas } \\
\text { visitas }\end{array}$ & $\begin{array}{c}\text { Acréscimo nas visitas por } \\
\text { mês }\end{array}$ & $\begin{array}{c}\text { Percentual/ } \\
\text { Mês }\end{array}$ \\
\hline 2 & $10 \%$ & Rotatividade & $\begin{array}{c}\text { Diminuição da rotatividade } \\
\text { por bimestre }\end{array}$ & $\begin{array}{c}\text { Percentual/ } \\
\text { Bimestre }\end{array}$ \\
\hline 3 & $15 \%$ & Rotatividade & $\begin{array}{c}\text { Diminuição da rotatividade } \\
\text { por semestre }\end{array}$ & $\begin{array}{c}\text { Percentual/ } \\
\text { Semestre }\end{array}$ \\
\hline 4 & $\begin{array}{l}20 \% \text { no } \\
\text { mínimo }\end{array}$ & Vendas & $\begin{array}{l}\text { Troca de plano simples para } \\
\text { semestral ou anual/trimestre }\end{array}$ & $\begin{array}{c}\text { Percentual/ } \\
\text { Trimestre }\end{array}$ \\
\hline 5 & $\begin{array}{l}20 \% \text { no } \\
\text { mínimo }\end{array}$ & Vendas & $\begin{array}{c}\text { Acréscimo na aquisição } \\
\text { deserviços após a liberação } \\
\text { dos novos planos }\end{array}$ & $\begin{array}{c}\text { Percentual/ } \\
\text { Mês }\end{array}$ \\
\hline 6 & $\begin{array}{l}15 \% \text { no } \\
\text { mínimo }\end{array}$ & Rotatividade & $\begin{array}{c}\text { Diminuição da rotatividade/ } \\
\text { semestre }\end{array}$ & $\begin{array}{c}\text { Percentual/ } \\
\text { Semestre }\end{array}$ \\
\hline 7 & $\begin{array}{l}20 \% \text { no } \\
\text { mínimo }\end{array}$ & Vendas & $\begin{array}{c}\text { Acréscimo na aquisição de } \\
\text { serviços após início dos planos de } \\
\text { pontuação }\end{array}$ & $\begin{array}{c}\text { Percentual/ } \\
\text { trimestre }\end{array}$ \\
\hline 8 & $\begin{array}{l}20 \% \text { no } \\
\text { mínimo }\end{array}$ & Vendas & $\begin{array}{c}\text { Acréscimo na quantidade de } \\
\text { serviços extras contratados pelos } \\
\text { coworkers }\end{array}$ & $\begin{array}{l}\text { Percentual/ } \\
\text { Trimestre }\end{array}$ \\
\hline 9 & $\begin{array}{l}20 \% \text { no } \\
\text { mínimo }\end{array}$ & Vendas & $\begin{array}{c}\text { Acréscimo na aquisição de } \\
\text { serviços por coworkers de áreas } \\
\text { novas no escritório }\end{array}$ & $\begin{array}{c}\text { Percentual/ } \\
\text { Trimestre }\end{array}$ \\
\hline
\end{tabular}

Fonte: Elaborado pelos autores (2017).

\section{CONCLUSÕES}

É possível visualizar a potencialidade do Coworking para muito além da partilha de espaço, movendose ao encontro de uma nova noção de relacionamento interpessoal no ambiente de trabalho. A organização estudada demonstrou ser inovadora ao disseminar um novo modelo de formas de trabalho, baseado no compartilhamento e estímulo ao networking, empreendedorismo e trabalho colaborativo. 0 espaço é ideal às empresas que buscam um ambiente com uma boa estrutura e com custo competitivo. Além disso, propicia oportunidades de novos negócios e parcerias entre os empreendedores.

Entretanto, as empresas devem continuar aprimorando seus serviços e inovando para fidelizar seus consumidores e conquistar cada vez mais usuários. Para isso, mesmo com todos os benefícios identificados na 
empresa, desenvolveu-se um modelo eficiente de avaliação da qualidade, além de propostas demelhorias que permitirão potencializar todas as características de economia compartilhada, aliando geração de valor aos serviços já praticados.

A partir da análise dos dados obtidos com a apliacação dos questionários, os autores apresentaram um modelo de avaliação da qualidade baseado nos indicares online, offline e inline. Na prática, os indicadores mostraram-se eficientes quanto a mensuração do impacto no que tange as necessidades dos usuários. Porém, há uma crítica ao estudo apresentado: alguns indicadores necessitam de padrões que possam ser mensurados com maior facilidade, em especial os que tem relação com o mercado (vide Padrões Tabela 4).

Como proposta de trabalho futuro, sugere-se a formulação de uma nova relação de indicadores com o apoio da própria empresa, no intuito de propor um modelo mais completo de avaliação e desenvolvendo melhorias contínuas. Também como projeto futuro, sugere-se a continuação deste trabalho, avaliando as melhorias por meio dos indicadores após sua aplicabilidade.

No que tange ao uso de indicadores da qualidade, os mesmos se mostram eficientes quanto a sua usabilidade. Com uso dos indicadores de qualidade, é possível avaliar quantitativamente cada melhoria e saber se a empresa está no caminho certo para melhor atender seus consumidores e conquistar mais clientes.

\section{REFERÊNCIAS}

BOSTMAN, Rachel; ROGERS, Roo. What's mine is yours: the rise of collaborative consumption. New York: Harper Business, 2010.

BRUNETE, Caio Braz.; BERTI, Eduardo Vazquez. Economia compartilhada e o confronto de ideais capitalistas. In: CONGRESSO NACIONAL DE INICIAÇÃO CIENTÍFICA, 16., 2016, São Paulo. Anais [...]. São Paulo: SEMESP/ENIAC, 2016. Disponível em: http://conic-semesp.org.br/anais/files/2016/trabalho-1000023574.pdf. Acesso em: 28 abr. 2016.

COWORKING BRASIL. 0 que é Coworking? 2017. Disponível em:https://coworkingbrasil.org/como-funcionacoworking/. Acesso em: 25 set. 2018.

FERREIRA, Karolina Matias et al. Economia compartilhada e consumo colaborativo: uma revisão da literatura. XII CONGRESSO NACIONAL DE EXCELÊNCIA EM GESTÃO, 12.; INOVARSE - RESPONSABILIDADE SOCIAL APLICADA, 3., 2016, Rio de Janeiro. Anais [...]. Rio de Janeiro: FIRJ AN, 2016.

GIL, Antônio Carlos. Como elaborar projetos de pesquisa. 5. ed. São Paulo: Atlas, 2010.

GURGEL JÚNIOR, Garibaldi Dantas; VIEIRA, Marcelo Milano Falcão. Qualidade total e administração hospitalar:explorando disjunções conceituais. Ciência \& Saúde Coletiva, n. 7, p. 325-334, 2002.

INVESTMENT STRATEGY \& RESEARCH. The sharing economy: new opportunities, new questions. Global Investor, Investment Strategy Research, 2015.

LOPES, J anice Correia da Costa. Gestão da qualidade: decisão ou constrangimento estratégico. 2014. Dissertação (Mestradoem Estratégia Empresarial) - Universidade Europeia, Lisboa, 2014.

MARCONI, Marina Andrade; LAKATOS, Eva. Fundamentos da metodologia científica. São Paulo: Atlas, 2010.

MARTIN, Chris J. The sharing economy: A pathway to sustainability or a nightmarish form of neoliberal capitalism? Ecological Economics, Reino Unido, v. 121, p. 149-159, 2016.

MENDES, Francisco Schertel; CEROY, Frederico Meinberg. Economia compartilhada e a política nacional de mobilidade urbana: uma proposta de marco legal.Brasília: Núcleo de Estudos e Pesquisas/CONLEG/Senado, 2015.

MIGUEL, Paulo Augusto Cauchick. Metodologia de pesquisa em engenharia de produção e gestão de operações. São Paulo: Campus, 2011. 
MORISET, Bruno. Building new places of the creative economy: The rise of coworking spaces. In: GEOGRAPHY OF INNOVATION INTERNATIONAL CONFERENCE, 2., 2014, Netherlands. Proceedings [...]. Netherlands: Utrecht University, 2014. p. 1-25. Disponível em: https://halshs.archives-ouvertes.fr/halshs00914075/document. Acesso em: 23 abr. 2017.

MUNHOZ, Anny Carolina Cantarero et al. Coworking e crowdsourcing: como modelos de negócios inovadores influenciam no desenvolvimento de start-ups. In: SEMINÁRIO EM ADMINISTRAÇÃO, 16., 2013, São Paulo. Anais [...]. São Paulo: ANPAD, 2013.

PALADINI, Edson Pacheco. Avaliação estratégica da qualidade. 2. ed. São Paulo: Atlas, 2011.

PALADINI, Edson Pacheco. Gestão estratégica da qualidade: princípios, métodos e processos. 2. ed. São Paulo: Atlas, 2009.

SCHOR, Juliet. Debating the sharing economy. Great Transition Initiative Essay. 2014. Disponível em: http://www.msaudcolumbia.org/summer/wpcontent/uploads/2016/05/Schor_Debating_the_Sharing_Economy.pdf. Acesso em: 01 set. 2018.

SHIRKY, Clay. Lá vem todo mundo: o poder de organizar sem organizações. Rio de Janeiro: Zahar, 2012.

SOARES, Juliana Maria Moreira; SALTORATO, Patricia. Coworking, uma forma de organização de trabalho: conceitos e práticas na cidade de são paulo. Atoz: Novas Práticas em Informação e Conhecimento, São Carlos, v. 4, n. 2, p. 8-19, jul. 2015. 